\title{
Perinatal Transfusion Medicine - Immunological Aspects
}

\author{
Dagmar Barz \\ Institute of Transfusion Medicine, University Hospital, Friedrich-Schiller-University Jena, Germany
}

The concept of compatibility is dependent on the specifity of immune responses. The immunology of reproduction, and in particular the tolerance of two genetically distinct organisms and their fruitful symbiosis, is one of the most imposing paradoxes in immunology. In normal human pregnancy, the allogeneic embryo is tolerated by the maternal immune system for about 40 weeks without general immunosuppression. The current knowledge concerning the most important cellular and soluble immunological components in the decidua and their interactions during pregnancy is presented by Poehlmann et al. [1].

During gestation, a temporary maternal tolerance against paternal antigens is induced by different mechanisms. Mothers produce antibodies directed against fetoplacental antigens of paternal origin. Different studies have shown evidence that blocking antibodies are present in child-bearing women which purportedly block paternal fetoplacental antigens. Diagnosing the presence of autoantibodies and/or alloantibodies against HLA, platelet or erythrocyte antigens in the sera of pregnant women is crucial as maternal antibodies are associated with severe clinical complications.

Antiphospholipid syndrome (APS) is an autoimmune disease which is characterized by the appearance of antiphospholipid antibodies. The most specific clinical features are thrombosis, recurrent miscarriages and fetal loss, and autoimmune thrombocytopenia. As highlighted by a review of Schleussner [2], this heterogeneous group of autoantibodies attracts growing interest and clinical significance in the treatment of recurrent pregnancy loss, placental insufficiency, preeclampsia, placental abruption, and thrombosis.

Fetal/neonatal alloimmune thrombocytopenia (FNAITP) is due to transplacental transfer of maternal IgG alloantibodies which react with an alloantigen on fetal platetelets that is inherited from the father and is lacking in the mother. FNAITP occurs in about 1 of 1,000 to 2,000 unselected pregnancies. However, platelet-specific alloantibodies are detectable in $25-30 \%$ of sera from mothers delivered from a thrombocytopenic offspring with suspected FNAITP. HLA antibodies develop in $20-30 \%$ of pregnancies in the absence of previous transfusion or fetomaternal blood transfer. A few case reports on suspected FNAITP suggested that HLA antibodies are responsible for the low platelet counts. However, most platelet immunologists hesitate towards a diagnosis of HLA class I-induced FNAITP even if these are the only detectable antibodies. Panzer [3] summarized the diagnostic requirements for an 'assumed' diagnosis of 'classical' platelet-specific, antibody-induced FNAITP and illustrated why the controversy on an HLA antibody-induced FNAITP is still ongoing.

In $1-2 \%$ of all pregnancies, recurrent spontaneous abortions occurs. Typical etiological causes for this event in early pregnancy include genetic, anatomic, hormonal and infectious factors. Recurrent spontaneous abortions can be associated with changes in the blood coagulation system, homocysteinemia, or APS. One underlying cause of unexplained recurrent abortions could be a maternal immunological malfunction preventing the mother from developing immune responses that are required for fetomaternal tolerance. Wegener et al. [4] reported on an immunotherapy using paternal lymphocytes as a promising therapeutic option for patients with recurrent miscarriages.

The actual overview on perinatal transfusion medicine will be completed by two other studies focusing on the pathogenesis and clinical relevance of antibodies against erythrocytes and platelets, which will be published in the next issue of TRANSFUSION MEDICINE AND HEMOTHERAPY.

\section{References}

1 Poehlmann TG, Fitzgerald JS, Busch S, Schleussner E, Gutiérrez G, Blois S, Arck PC, Kämmerer U, Szekeres-Bartho J, Markert UR: Reproductive immunology an update. Transfus Med Hemother 2006;33:DOI 10.1159/000096044.

2 Schleussner E: Impact of the antiphospholipid syndrome on complications during pregnancy. Transfus Med Hemother 2006;33:DOI 10.1159/000096046.

3 Panzer S: Controversy: HLA antibodies responsible for fetal/neonatal alloimmune thrombocytopenia - an update Transfus Med Hemother 2006;33:DOI $10.1159 / 000096045$

4 Wegener S, Schnurstein K, Hansch S, Bolz M, Briese V, Sudik R. Wegener R, Busecke A, Müller H: Immunotherapy with paternal lymphocytes for recurrent miscarriages and unsuccessful IVF treatment. Transfus Med Hemother 2006;33: DOI 10.1159/000096125.

\begin{tabular}{ll}
\hline KARGER & @ 2006 S. Karger GmbH, Freiburg \\
Fax +49 7614520714 & Accessible online at: \\
$\begin{array}{l}\text { E-mail Information@Karger.de } \\
\text { www.karger.com }\end{array}$ & www.karger.com/tmh
\end{tabular}

Prof. Dr. Dagmar Barz

Institut für Transfusionsmedizin

Universitätsklinikum, Friedrich-Schiller-Universität Jena

Stoystraße 3, 07743 Jena, Germany

Tel. +49 3641 9354-61, Fax -62

E-mail dagmar.barz@med.uni-jena.de 